\title{
Evaluation of Current Status of Urine and Serum Biomarkers in the Diagnosis and Follow-up of Bladder Cancer: Review
}

\author{
(1) Mehmet Yıldızhan ${ }^{1}$, (1) Hakan Gemalmaz ${ }^{2}$ \\ ${ }^{1}$ Ankara State Hospital, Clinic of Urology, Ankara, Turkey \\ ${ }^{2}$ Adnan Menderes University Faculty of Medicine, Department of Urology, Aydın, Turkey
}

\begin{abstract}
Bladder cancer is a very common, aggressive malignant tumor. It is associated with high recurrence and mortality rates. Early detection of bladder cancer and recurrences is very vital to ensure long survival. The main purpose of screening methods is to detect the disease at an early stage. Diagnosis and follow-up of these patients are currently based on endoscopic approaches, which is expensive and invasive, and urinary cytology with low sensitivity. In order to reduce the burden of cystoscopic evaluation, which is the standard approach used in the follow-up, urine strip tests have been used in order to evaluate the presence of hematuria, and cost effective and relatively high-performance molecular markers, respectively. However, there is still no safe biomarker to replace the conventional approach. Bladder tumors exhibit a wide heterogeneity with various molecular differences associated with different morphological symptoms and disease phenotypes. Therefore, the introduction of biomarkers that evaluate the aggressiveness of the disease, the risk of progression, the likelihood of recurrence and prognosis will improve patient management. In addition, integrating the use of molecular biomarkers with conventional pathological evaluation will allow us to make clinical decisions, such as the selection of adjuvant and salvage treatment.
\end{abstract}

Keywords: Bladder cancer, urinary biomarkers, molecular markers

\section{Introduction}

Bladder cancer is the second most common cancer in the United States among genitourinary cancers (1). In the world, it is the $11^{\text {th }}$ most common cancer among all cancers (2). The worldwide standardized incidence for age was 8.9 for males (100,000 person-year) and 2.2 for females (2008 data), while it was 27 for males and six for females in Europe (2). The incidence is generally increasing in developed countries. Transitional epithelial cell cancers are the most common histological type in $90 \%$ of cases, but squamous cell cancers and adenocarcinomas are other types of cancer seen in the bladder (3).

Diagnosis of bladder cancer is made by cystoscopy, cytology and pathological evaluation of the excised material. If bladder cancer was detected or urinary cytology was found positive, diagnostic cystoscopy is omitted and biopsies from suspected areas or tumor resection are performed under anesthesia (4). However, despite initial treatment, tumor recurrence occurs after endoscopic resections in $30-85 \%$ of the cases, and $16-25 \%$ of them develop higher grade tumors (3). Approximately $10 \%$ of tumors without muscle invasion develop invasive or metastatic cancer during follow-up.

After the diagnosis of bladder cancer, the follow-up procedures for the disease are as important as the diagnosis of the disease. Cystoscopy and cytological evaluation of urine are recommended routinely. However, cystoscopy being an invasive procedure and low sensitivity of cytological evaluation of urine have revealed the necessity of identifying new markers.

In this review, bladder tumor biomarkers that are still in use or are under development in diagnosis and/or follow-up are reviewed.

\section{Urine Cytology}

Urinary cytological evaluation, which starts with the identification of abnormal cells in the urine sample, is a non-invasive urine marker commonly used in the diagnosis of bladder tumor. Noninvasive collection of urine and the tendency of cancerous cells 
to shed as a result of loss of cohesion make this examination easy and specific to high-grade lesions. For better evaluation, the method of urine collection, detailed clinical history, treatment and catheter insertion should be reported.

The urothelium consists of superficial cells with large cytoplasm and sometimes mucin, intermediate cells with less cytoplasm under it, and basal cells at the bottom. Cytological samples include mostly superficial and intermediate cells. Infection, catheter application, stones and various treatments may lead to reactive changes. Reactive changes are difficult to distinguish from papilloma, papillary urothelial neoplasia with low malignant potential and low-grade papillary urothelial carcinoma.

Patients with bladder cancer are classified as low or high-grade tumors according to their cytological features. Sensitivity and specificity are very high in high-grade papillary cancers and in situ cancers. In the literature, the diagnostic accuracy of cytological examination in low-grade cancers was reported as $17 \%-70 \%$ for spontaneous urine samples in original studies. This rate is $95 \%-100 \%$ in high-grade papillary and in situ cancers (5).

High sensitivity and specificity are important, as in situ cancer area may not be recognized by cystoscopy and in situ lesions often accompany invasive, high-grade, multifocal tumors $(6,7)$. According to a recent study, sensitivity and specificity rates of urine cytology was $38 \%$ and $98.3 \%$, respectively. There was no significant difference between spontaneous urine and washing $(8,9)$. In order to better visualize cancer cells, urine samples to be used in cytology should be taken from patients who are well hydrated. The urine sample to be examined should be taken from the first morning urine. Positivity of urine cytology findings, even if upper urinary tract and bladder imaging results are negative, may indicate cancer elsewhere in the urinary tract such as calyxes or ureters. Furthermore, a negative result of urinary cytology does not necessarily indicate the absence of a low-grade bladder tumor (10). All of these causes have encouraged the search for more reliable urine tests for the diagnosis of urothelial malignancy.

\section{Microscopic Hematuria}

Hematuria is the most common sign of bladder cancer. It is usually detected using a dipstick test. The test is easy to use and cost-effective. Sensitivity and specificity for microscopic hematuria have been reported as $91 \%$ and $99 \%$, respectively (11). Hematuria is a common finding in the general population and is not only associated with bladder cancer. For populationbased screening tests, bladder cancer was reported in 16-24\% of men with hematuria who were older than 50 years; however, it was not detected in $32 \%$ of bladder cancers (12). Hematuria is intermittent in most patients (13). Recurrence increases the sensitivity of the hemoglobin dipstick test and the number of patients with false-positive findings that may lead to cystoscopy (reducing specificity). Patient compliance to homebased daily repeated tests is generally good (97.7\%) (14). Weekly hematuria tests are useless, and researchers recommend daily testing for 10-14 days every 6-12 months (11). It is not recommended to use first urine in the morning, and urine following excessive physical activity or sex. High false-positive rates are associated with other genitourinary cancers, colic pain, anticoagulant treatments (Warfarin, salicylates, NSAIDs), and other pathologies (glomerulonephritis, urinary stones) that cause hematuria $(11,12,13,14,15)$.

\section{Urine Tumor Markers}

The most common presenting symptom of bladder cancer patients is asymptomatic microscopic hematuria or painless macroscopic hematuria. The rate of symptomatic patients is often difficult to say because the symptoms are intermittent and cannot be shown in screening. However, the use of urinary markers, which have recently been developed for early detection of urinary malignancies, gives hope for early diagnosis. The use of these markers can reduce the number of regular cystoscopies performed to control non-muscle-invasive bladder cancer relapses and ultimately result in significant cost savings. Likewise, prediction of the patient population that will show progression may lead to an increase in disease-related survival (16).

Urine is in a continuous relationship with the urothelium in the renal pelvis, ureter and bladder starting from the calyces. Therefore, the use of urine samples seems to be more rational in the investigation of a marker for urothelial cancers (17).

An ideal marker:

- Should be non-invasive and easy to apply technically,

- Should be cheap,

- Should be reliable and repeatable,

- Should have high specificity and sensitivity,

- $\quad$ Should ensure early detection of high-risk tumors (e.g. carcinoma in situ) and ensure that the chance of curative treatment is not missed (18).

\section{A. Molecular Markers in Urine}

\section{Bladder Tumor Antigen Test}

It is based on the detection of human complement factor $\mathrm{H}$-associated protein in urine that is produced in bladder cancer cell. In cell cultures, normal cells were unable to express $\mathrm{H}$-associated proteins. The bladder tumor antigen test (BTA)Stat assay is a qualitative immunoassay using two different monoclonal antibodies. BTA Stat is an immunochromographic, qualitative, NMP22-like test, approved by the United States Food and Drug Administration (FDA) for follow-up, not for screening or diagnosis. In many studies, the sensitivity varies between $36-89 \%$ (19). Specificity is high in healthy individuals (97\%). However, in benign genitourinary diseases (hematuria, benign prostatic hyperplasia, BCG use, urinary diversions, urinary stone, cystitis, nephritis), it decreases to $46 \%$. This leads to false positive results by binding of complement factor $\mathrm{H}$, which is already present in the serum at a constant amount of 0.5 $\mathrm{mg}$, to erythrocytes in the urine. BTA-stat is superior to urinary cytology in detecting low-grade cancers. In a large, multicenter study, 95\% specificity was demonstrated in healthy volunteers without genitourinary disease. However, the specificity shows a significant decrease in patients with additional disease; it is around $88 \%$ in patients with benign prostatic hyperplasia and 
$50 \%$ in patients with urolithiasis. Specificity decreases to $33 \%$ after interventions to the bladder or prostate $(20,21,22)$. The BTA-stat test should be interpreted with caution in patients with microscopic hematuria. The test is not safe as urine leads to false positivity when it is very bloody (23).

BTA-Trak test is a quantitative ELISA (Enzyme Linked Immunosorbent Assay) test and two monoclonal antibodies against complement factor $\mathrm{H}$ and complement factor $\mathrm{H}$ dependent protein are used. The overall sensitivity and specificity of the BTA-Trak test are $66 \%$ and $69 \%$, respectively. The accuracy of the BTA-Trak test in low-grade tumors is better than the BTA-Stat test. The most important factor limiting the use of this test is high false-positive rates (24).

\section{Nuclear Matrix Protein Test}

The nuclear matrix protein is part of the internal framework of the cell nucleus and plays a role in DNA replication, transcription and transfer to RNA and possibly regulation of gene expression. This protein is associated with spindle bodies formed during mitosis and may be responsible for the proper and regular distribution of chromatids in daughter cells. When inappropriate distribution of chromatids occurs during mitosis, there is a 25 -fold increase in nuclear mitotic apparatus proteins in tumor cells compared with normal bladder epithelial cells, such as in bladder tumors (25). Compared with normal tissue and transitional cells, there is at least a 10-fold increase in nuclear mitotic apparatus proteins in cancer tissue. There are two different nuclear matrix protein tests (NMP22) used to detect NMP22 in urine. The original NMP22 bladder cancer test kit is a laboratory-based, quantitative, sandwich-type enzyme immunoassay. The second test is NMP22 BladderChek, which contains a qualitative, NMP22-detecting antibody. Both tests were approved by the FDA for follow-up of bladder tumors. In addition, the NMP22 BladderChek test can be used for screening patients at risk for bladder tumors.

The sensitivity and specificity of NMP22 ELISA from various studies vary between $19-100 \%$ and $55-92 \%$, respectively. This variability arises from the use of different predictive values in various studies and the diagnosis of recurrent tumor versus primary tumor diagnosis.

NMP22 has high false-positive rates in patients with inflammatory status, renal and bladder stones, foreign bodies in the body, intestinal interposition, other genitourinary cancer, and proteinuria (26). The BladderChek test has recently been studied by Grossman et al. (27) in a prospective study of a total of 1331 patients with lower urinary tract symptoms such as hematuria and dysuria, and with a history of smoking. In this study, NMP22 was compared with urinary cytology. The test has been shown to have $55.7 \%$ sensitivity and $85.7 \%$ specificity in the diagnosis of bladder tumors. For urine cytology, these values were reported as $15.8 \%$ and $99.2 \%$, respectively.

\section{NMP52}

It is a 52-kilodalton nuclear matrix protein. It measures by using ELISA with polyclonal rabbit antibody. In a study of 149 patients with bladder cancer, the sensitivity of NMP52 test was $92 \%$ in the diagnosis of squamous cell carcinoma, $98 \%$ in the diagnosis of variable epithelial cell carcinoma, and $100 \%$ in the diagnosis of adenocarcinoma of the bladder. The specificity of the test was found to be $94 \%$ (28).

\section{BLCA-1 and BCLA-4}

BLCA-1 and BLCA-4 are nuclear transcription factors in bladder tumors. BLCA-1 is not released from non-malignant urothelium. BLCA-4 is a factor released from both tumor and benign areas adjacent to tumor, but not from non-malignant bladder $(29,30)$. BLCA-4 is measured in urine by ELISA. It has been reported that its sensitivity reaches $89-96 \%$ and its specificity reaches $100 \%$ $(31,32)$. This protein increases IL- $1 \alpha$, thrombomodulin and IL-8 levels and affects the pathogenesis of bladder tumor (33).

In a study of 25 bladder cancer cases and 46 controls, BLCA- 1 ELISA was shown to have a sensitivity of $80 \%$ and a specificity of $87 \%$ (34). BLCA-4 test has been shown to have sensitivity and specificity of more than $90 \%$ in two separate studies $(35,36,37,38)$. In a study conducted by Van Le et al. (39) in 75 patients with primary bladder cancer, the sensitivity and specificity were $89 \%$ and $95 \%$, respectively. BLCA-4 is a potential useful marker for bladder cancer screening because of its high sensitivity and specificity. However, it has not been sufficiently tested for survival.

\section{Survivin}

It is an antiapoptotic protein. It is an inhibitor of the apoptosis family (40). Survivin is found in $10-30 \%$ of bladder tumor tissues. The sensitivity of urine survivin levels measured using a bio-dot measuring apparatus is between $42.5-100 \%(41,42,43)$. High levels of survivin increase the risk of bladder cancer and the likelihood of having a higher-grade tumor (44). Clinical use in bladder cancer has been questioned because of its low specificity.

\section{Urinary Bladder Cancer Test}

It is an ELISA test that investigates the presence of fragments of cytokeratin 8 and 18 in urine. Cytokeratin 8 and 18 are normal structural components of the cell. Increased expression has been observed in transitional epithelial cell cancers, especially in high-grade ones (45). In a study by Babjuk et al. (46) in which recurrent tumor formation is monitored in 88 patients with non-muscle invasive bladder cancer, sensitivity was 54\% and specificity was $97 \%$. They concluded that it could not be used to reduce the number of cystoscopies in routine urology practice due to its low sensitivity. Mungan et al. (47) evaluated the diagnostic value of urinary bladder cancer test (UBC) in 100 patients with non-muscle invasive bladder tumors and reported sensitivity, specificity, positive and negative predictive values as $20.7 \%, 79.2 \%, 28.6 \%$ and $71.3 \%$, respectively. With these results, they concluded that UBC test was insufficient in the follow-up of patients with bladder tumors.

\section{CYFRA 21.1 Test}

It is an ELISA based assay that allows the detection of cytokeratin 19 fragments by means of two monoclonal antibodies (BM19.21 and KS19.1). In a study by Fernandez-Gomez et al. (48) and colleagues in 446 patients with Ta and T1 bladder cancer, 125 patients had recurrence, and the sensitivity and specificity of the test were found to be $43 \%$ and $68 \%$, respectively. Cut-off 
value was accepted as $4 \mathrm{ng} / \mathrm{mL}$ and 12 patients with Ta tumor could not be determined. When the cut-off value was accepted as $1.5 \mathrm{ng} / \mathrm{mL}$, the rate of detecting Ta recurrences increased by $73 \%$, but its specificity decreased to $43 \%$. They emphasized that this test was not a suitable marker for follow-up in patients with bladder cancer.

\section{Fibrinogen Degradation Products, ACCU-DX}

Cancer cells produce an angiogenic factor that induces vascular endothelium, called vascular endothelial growth factor. This factor increases vascular permeability in tumor tissue. This leads to the passage of blood and plasma proteins, such as plasminogen, fibrinogen, coagulation factors, into the extravascular space. Fibrinogen is converted to fibrin and binds to plasminogen and converts to plasmin. Plasmin, a potent proteolytic enzyme, breaks down fibrinogen and fibrin into Fibrinogen degradation products (FDP). FDP circulates and is also found in urine in patients with bladder cancer. Urine FDP can be measured by latex agglutination test, monoclonal antibody-based ELISA and monoclonal antibody immunassay methods $(49,50,51,52,53)$. The ACCU-DX test is a qualitative test using murine monoclonal antibodies specific for FDP. However, the availability of this test is low in the presence of hematuria because these antibodies also interact with intact fibrinogen, which is typically found in human serum (54). FDPs are either absent or extremely low in the urine of healthy individuals. In some inflammatory events, FDP may be detected in the urine, but the detection of FDP in the urine is generally interpreted in favor of transitional epithelial cell cancer. FDP levels in urine increase as tumor stage and grade increase. When used together with cytology, its sensitivity increases to $75-80 \%$ (20).

\section{Hyaluronic Acid, Hyaluronidase Test}

Hyaluronic acid (HA) forms the extracellular glycosaminoglycan layer that protects tumor cells from the control of the immune system. Adhesion and migration of tumor cells is also facilitated by this layer. The HA-Hyaluronidase (HAase) assay is a combination of two similar ELISA assays. It measures the urinary $\mathrm{HA}$ and HAase levels. HA test can detect bladder cancer regardless of tumor grade and HAase test detects high-grade tumors. The combination of HA test-HAase test has a sensitivity of $83-94 \%$ in detecting both primary and recurrent tumors $(41,42)$. It has sensitivity between $75 \%$ and $100 \%$ in both low-grade/stage and high-grade/stage tumors $(55,56)$. In addition, in the followup of bladder cancer recurrence with the HA-HAase test, even a false-positive value indicates an increased risk of recurrence by 4 to 10 times within 5 months (57). The specificity of HA-HAase test between normal individuals and patients with benign urological conditions is $80 \%(41,42)$.

\section{B. Tests with Shed Cells into the Bladder Lumen}

\section{ImmunoCyt}

In this test, urine specimens containing tumor cells shred into the lumen of the bladder are used in patients with bladder tumors. It is an immunohistochemical test that detects sulfated mucin glycoproteins and carcinoembryonic antigen on the surface of bladder tumor cells. Assay is performed using three fluorescent stained monoclonal antibodies. These fluorescent monoclonal antibodies are 19A211, M344 and LDQ10. The main advantage of this test is the high rate of detecting low grade and well-differentiated tumors. The disadvantage is that false positive and negative rates are high and an experienced cytopathologist is needed. The detection of a single fluorescent cell in one sample represents the positivity of the assay. In the study of Lodde et al. (58) in 216 patients, sensitivity was $84 \%$ and specificity was $78 \%$.

\section{Lewis $X$ antigen}

It is based on the detection of a blood group antigen that is not normally found in urinary transitional epithelial cells using monoclonal antibodies. This blood group antigen is synthesized by all cancerous cells, regardless of tumor grade and stage. In the study of spot urine samples of 260 patients, Pode et al. (59) found sensitivity as $79.8 \%$ and specificity as $86.4 \%$, and Cis was found to be $100 \%$. With the evaluation of two different urine specimens, Golijanin et al. (60) stated that the sensitivity of Lewis $X$ antigen test increased from $81.2 \%$ to $97 \%$, and the specificity increased to $85.5 \%$.

\section{DD23}

DD23 is a monoclonal antibody that detects a protein dimer released from bladder cancer cells. It is an immunohistochemical test with alkaline phosphatase bound to monitor tumor cells in urine. In two controlled trials, DD23 showed high sensitivity between $70-80 \%(61,62)$. This marker has high sensitivity in both low-grade tumors (approximately 70\%) and high-grade tumors (approximately 87\%). Its sensitivity slightly increases when used in combination with urinary cytology (78-85\%). However, the specificity of DD23 is about $60 \%$ and the specificity of the samples obtained by washing is lower $(61,62)$.

\section{Cytokeratin 20}

Cytokeratins are intermediate filament proteins of epithelial cells. Cytokeratin 20 is specifically expressed by the bladder and gastrointestinal epithelium. It can also be detected in normal cells in scans but has been upregulated in carcinoma patients. In two studies, the mean sensitivity and specificity of cytokeratin 20 were found to be $85 \%$ and $76 \%$, respectively $(63,64)$. Studies comparing cytokeratin 20 with other markers other than urine cytology have not yet been performed.

\section{Telomerase}

Most cells in the body can proliferate in a limited number before losing their ability to divide. Chromosome terminations are called telomere. The ability to continuously proliferate is acquired by expression of the telomerase gene. Telomerase is normally expressed in cells such as stem cells or gametes, which must be divided into an unlimited number. Telomerase immortalizes the chromosome or telomeres by maintaining the ends normally shortened in each division. Although active telomerase is important for survival in malignant cells and for long survival in normal cells, telomerase itself has no effect of inducing a malignant phenotype. However, the presence of oncogene and/or tumor suppressor gene inactivation in 
addition to telomerase may cause malignant transformation. Genitourinary cancers have a high level of telomerase activity as in all cancers $(65,66,67)$. Two different methods have been developed to evaluate telomerase activity in tissue. First, TRAP (telomeric repeat amplification protocol) is based on the telomeric amplification protocol by ELISA or RT-PCR. Second, hTERT (human telomerase reverse transcriptase) is based on the measurement of mRNA levels by RT-PCR method.

Increased telomerase levels by $90 \%$ especially in high-grade and staged cancers made it an important tumor marker (68). In their study of 200 bladder cancer patients (primary or recurrent distinction), Eissa et al. (69) recruited 85 benign bladder lesions and 30 healthy patients as the control group. They found the sensitivity to detect bladder cancer as $96 \%$.

Telomerase activity was evaluated by a polymerase chain reaction test using TRAP. In the detection of bladder tumors, the sensitivity of the telomerase test is between $7 \%$ and $100 \%$, usually $70-86 \%$, and the specificity ranges from $24 \%$ to $90 \%$, usually $60-70 \%(70,71,72,73)$. In a study conducted to determine the TRAP threshold range in 2005, a sensitivity of $90 \%$ and a specificity of $88 \%$ when the threshold value was taken as 50 enzyme units (74).

\section{UroVysion Fluorescence In Situ Hybridization (UroVysion FISH)}

It is a multi-targeted, multicolour fluorescent in situ hybridization (FISH) test that involves staining urine cells with 4 denatured centromeric chromosome enumeration probes. It detects chromosome 3 (spectrum red), chromosome 7 (spectrum green), chromosome 17 (spectrum aqua) and locus-specific probe 9p21 (spectrum gold). Cells are examined under fluorescence microscopy. Diagnostic criteria for bladder cancer in the UroVysion test are: five and/or more cells with polysomy of two or more chromosomes, isolated gain of a single chromosome in $10 \%$ or greater cells, and homozygous deletion of 9p21 in 20 or more cells. Four types of genetic abnormalities (polysomy, tetrasomy, trisomy, and homozygous 9p21 deletion) were observed in the UroVysion examination of patients with bladder cancer. In various studies, the sensitivity of UroVysion test ranges from $69 \%$ to $87 \%(75,76)$. This test has been approved by the FDA for the follow-up of patients with bladder tumors and for the detection of bladder tumors in patients with hematuria. UroVysion test has a very good sensitivity rate (83-100\%) in detecting Tis and high grade/high stage tumors. However, sensitivity is not good in detecting low-grade/lowgrade tumors $(76,77)$.

Despite a normal cystoscopy, some of the patients with positive FISH test were suggested to develop urothelial cancer after a while. Many studies have reported positive bladder biopsy within 12 months in $85 \%$ to $89 \%$ of patients with positive FISH tests $(77,78)$. However, some other studies have shown that the recurrence rate after positive FISH test and negative cystoscopy is $<50 \%$ (79).

\section{MicroRNA Markers}

MicroRNAs (miRNAs) are non-coding RNAs that regulate gene expression after transcription (80). Because they are stable in urine and are more resistant to nuclease degradation due to their small size, they can be used as an ideal bladder marker (81). There are many nucleases in the urine, and a large number of tests that analyze mRNA expression are not successful due to target degradation. Recently, urinary miRNA expression has been reported and upregulation of miRs-126/182/199a has been found to differentiate between healthy and bladder tumor patients (82). In spite of the inability to distinguish the expression of these miRNAs in normal and malignant urothelium, the combination of mi-126 and 182 was found in $77 \%$ of bladder tumor cases (83). Further study of these markers is needed. In a study of 485 bladder cancer patients presenting with macroscopic hematuria in Australia, urine cytology, NMP22 and MicroRNA efficacy were evaluated. MicroRNA showed a higher specificity rate of $85 \%$ than urine cytology and NMP22. However, the presence of urinary stone causes false positive results. In addition, it was reported that specificity was affected at a low rate with gender, age and creatinine level (84). In a similar study conducted in the UK, 121 urine samples from 68 patients with bladder cancer and 53 non-bladder cancer samples were subjected to polymerase chain reaction using fifteen microRNA fragments. Results reported that urinary microRNAs were successful at a rate of $94 \%$ in detecting urothelial cancers (85).

\section{Microsatellite Analysis}

Microsatellite analysis has been mentioned in the literature since 1997 and its success in detecting low-grade bladder cancers has been evaluated. It is a polymerase chain reaction test that recognizes the tumor DNA. Recent studies have reported recurrence rates of $83 \%$ in those with positive microsatellite test and $22 \%$ in those with negative test $(86,87)$.

\section{Other Markers}

\section{Microtubule-associated Proteins}

It is a microtubule-associated protein (MAP) localized in the Tau $17 q 21$ gene. It regulates the cell cycle of stathmin, which is the protein disrupting microtubule stabilization. In case of mutation or deregulation, it leads to uncontrolled cell proliferation (88). High expression or activity of stathmin may be indicative of metastasis and may be associated with poor prognosis. In a recent study examining MAP levels in 32 patients with bladder cancer, high levels of tau and stathmin protein measured before intravesical taxane treatment were associated with decreased recurrence-free survival (88). Multivariate analysis showed that tau positivity was an independent risk factor for recurrencefree survival. Stathmin-positive patients had a recurrence-free survival of 16 months shorter than the negative ones. It is an experimental marker used to determine prognosis.

\section{Mammary Serine Protease Inhibitor}

Mammary serine protease inhibitor (Maspin) is a protein encoded by SerpinB5s localized in the 18q21.3 gene (89). The protein, a gene product, acts as a tumor suppressor gene and reduces the invasion and metastasis ability of cancer cells. Acikalin et al. (89) conducted a study to evaluate the effect of maspin by immunohistochemical method in 68 newly diagnosed T1 bladder cancer patients. They showed that 
patients with maspin negative were 2.2 times more likely have recurrence than positive ones. Maspin negative patients were 4.3 times more at risk for progression than maspin positive patients. Decreased expression of maspine was found to be an independent risk factor for recurrence and progression.

\section{Tumor Associated Trypsin Inhibitor}

It is a low molecular weight (6 kilodalton) trypsin inhibitor used in bladder cancer screening. The role of trypsin in cancer pathogenesis is not yet known. The expression of tumor associated trypsin inhibitor (TATI) in urine was determined by an immunofluorometric method. In 80 patients with primary bladder cancer, Gkialas et al. (90) found a sensitivity of $85.7 \%$ and a specificity of $76 \%$ in a screening study using TATI. However, no further studies have been conducted to support this data.

\section{Conclusion}

Although many studies have been published in the literature to identify an ideal tumor marker in recent years, most of these tests have better sensitivity and lower specificity in the diagnosis of bladder cancer. Therefore, it is not uncommon to use unnecessary biopsy and imaging techniques because of false-positive results. Whether such tests can provide additional information in decision-making, treatment and prognosis in non-muscle invasive bladder cancer is not yet known due to the lack of multicenter prospective data on the subject. The combined use of current novel markers can result in higher performance, eliminating the drawbacks of one test by the advantages of another test. For a valuable test in detection of bladder cancer; sensitivity and negative predictive value are important. Sensitivity and negative predictive value should be above $90 \%$ in all tumors if they are to replace cystoscopy. It should be over 95\% in "dangerous" high-grade tumors (55). Today, there are no tests that meet these criteria. The use of urinary tumor markers is optional in low and moderate risk disease in NCCN (National Comprehensive Cancer Network) 2015 guidelines and the degree of recommendation is $2 \mathrm{~B}$.

There is currently no scientific guideline to routinely recommend the use of either of these tests in urology practice, diagnosis, or follow-up. In summary, urinary cytology and cystoscopy are the gold standard in the diagnosis and follow-up of bladder tumors.

\section{Ethics}

Peer-review: Internally peer-reviewed.

\section{Authorship Contributions}

Concept: M.Y., Design: M.Y., Data Collection or Processing: M.Y., Analysis or Interpretation: H.G., Literature Search: M.Y., Writing: M.Y.

\section{Acknowledgements}

Publication: The results of the study were not published in full or in part in form of abstracts.

Contribution: There is not any other contributors who may not be listed as authors.

Conflict of Interest: No conflict of interest was declared by the authors.
Financial Disclosure: The authors declared that this study received no financial support.

\section{References}

1. Dinçel Ç. (edit) Üroonkoloji kitabı. Genişletilmiş ikinci baskı. Mete Basımevi. Izmir 2013;251-523.

2. Ferlay J, Bray F, Forman D, et al. Cancer Incidence and Mortality Worldwide: IARC Cancer Base No.10 2010, International Agency for Research on Cancer: Lyon, France. Globocan 2008 v1.2

3. Walsh PC, Retik AB, Vaughan ED, et al Campbell Urology. 8. Baskı. 4.Cilt. Ankara: Güneş Kitabevi; 2005. s.2732-65.

4. Babjuk $M$, Böhle A, Burger $E$, et al. Guidelines on non-muscle invasive baldder cancer 2014.

5. Parker J, Spiess P. Current and Emerging Bladder Cancer Urinary Biomarkers. ScientificWorldJournal 2011;11:1103-1112.

6. Pruthi RS. The value of urine cytology in the diagnosis and management of urinary tract malignancies. Pathology Case Reviews 2000;5:102-105.

7. Turbat-Herrera EA, Colom $\mathrm{H}$. The dilemma of urinary cytology revisited. Pathology Case Reviews 2000;5:95-101.

8. Planz B, Jochims E, Deix T, et al. The role of urinary cytology for detection of bladder cancer. Eur J Surg Oncol 2005;31:304-308.

9. Badalament RA, Fair WR, Whitmore WF, et al. The relative value of cytometry and cytology in the management of bladder cancer. Semin Urol 1988;6:22-30.

10. Tribukait B, El-Bedeiwy A, Shaaban AA. Prediction of lymph node metastases in bladder carcinoma with deoxyribonucleic acid flow cytometry. J Urol 1990;144:884-887.

11. Golijanin D, Shapiro A, Pode D. Immunostaining of cytokeratin 20 in cells from voided urine for detection of bladder cancer. J Urol 2000;164:1922-1925.

12. Rotem D, Cassel A, Lindenfeld N, et al. Urinary cytokeratin 20 as a marker for transitional cell carcinoma. Eur Urol 2000;37:601-604.

13. Fernandez-Gomez J, Rodriguez-Martinez JJ, Barmadah SE, et al. Urinary CYFRA 21.1 is not a useful marker for the detection of recurrences in the follow-up of superficial bladder cancer. Eur Urol 2007; 51:1267-1274.

14. Bavaccini S, Casadio V, Amadori D. The current role of telomerase in the diagnosis of bladder cancer. Indian J Urol 2005;25:40-46.

15. Ito $H$, Kyo $S$, Kanaya T. Expression of human telomerase subunits and correlation with telomerase activity in urothelial cancer. Clin Cancer Res 1998;4:1603-1608.

16. Mitra AP, Cote RJ. Molecular screening for bladder cancer: progress and potential. Nature Reviews Urology 2010;11-20.

17. Tilki $D$, Burger $M$, Dalbagni $N$, et al. Urine markers for detection and surveillance of non-muscle-invasive bladder cancer. Eur Urol 2011; 60:484-492.

18. Babjuk M, Böhle A, Burger $M$, et al. Guidelines on Non-muscle invasive bladder cancer (Ta,T1 and CIS). EAU 2015.

19. Pardoll DM, Vogelstein B, Coffey DS. A fixed site of DNA replication in eukaryotic cells. Cell 1980;19.

20. Ramakumar S, Bhuiyan J, Besse JA, et al. Comparison of screening tests in the detection of bladder cancer. J Urol 1999;161:388-394.

21. Sarosdy MF, Hudson MA, Ellis W], et al. Improved detection of recurrent bladder cancer using Bard BTA Stat test. Urology 1997; 50:349-353.

22. Pode D1, Shapiro A, Wald M, et al. Noninvasive detection of bladder cancer with the BTA stat test. J Urol 1999;161:443-446.

23. Oge O, Kozacı D, Gemalmaz H. The BTA stat test is nonspecific for hematuria: an experimental hematuria model. J Urol 2002;167:13181319; discussion 1319-20.

24. Compton DA, Cleveland DW. Numa is required for the proper completion of mitosis. J Cell Biol 1993;120:947-957. 
25. Carpinito GA1, Stadler WM, Briggman JV, et al. Urinary nuclear matrix protein as a marker for transitional cell carcinoma of the urinary tract. J Urol 1996;156:1280-1285.

26. Ponsky LE, Sharma S, Pandrangi L, et al. Screening and monitoring for bladder cancer: Refining the use of NMP22. J Urol 2001;166:75-78.

27. Grossman HB, Messing E, Soloway M, et al. Detection of bladder cancer using a point-of-care proteomic assay. JAMA 2005;293:810-816.

28. Attallah AM, Sakr HA, Ismail H, et al. An office-based immunodiagnostic assay fordetecting urinary nuclear matrix protein 52 in patients with bladder cancer. BJU Int 2005;96:334-339.

29. Yokota K, Kanda K, Inoue $Y$, et al. Semi-quantitative analysis of telomerase activity in exfoliatedhuman urothelial cells and bladder transitional cell carcinoma. Br J Urol 1998;82:727-732.

30. Lee MY, Tsou MH, Cheng MH, et al. Clinical application of NMP22 and urinary cytology in patients with hematuria or a history of urothelial carcinoma. World J Urol 2000;18:401-405.

31. Weikert S, Krause H, Wolff I, et al. Quantitative evaluation of telomerase subunits in urine as biomarkers for noninvasive detection of bladder cancer. Int J Cancer 2005;117:274-280.

32. Sanchini MA, Gunelli R, Nanni O, et al. Relevance of urine telomerase in the diagnosis of bladder cancer. JAMA 2005;294:2052-2056.

33. Skacel M, Fahmy M, Brainard JA, et al. Multitarget fluorescence in situ hybridization assay detects transitional cell carcinoma in the majority of patients with bladder cancer and atypical or negativ e urine cytology. J Urol 2003;169:2101-2105.

34. Myers-Irvin JM, Landsittel D, Getzenberg RH. Use of the novel marker BLCA-1 for the detection of bladder cancer. J Urol 2005;174:64-68.

35. Myers-Irvin JM, Van Le TS, Getzenberg RH. Mechanistic analysis of the role of BLCA-4 in bladder cancer pathobiology. Cancer Res 2005;65:7145-7150.

36. Van Le TS, Myers J, Konety BR, et al. Functional characterization of the bladder cancer marker, BLCA-4. Clin Cancer Res 2004;10:1384-1391.

37. Konety BR, Nguyen TS, Brenes G, et al. Clinical usefulness of the novel marker BLCA-4 for the detection of bladder cancer. J Urol 2000; 164:634-639.

38. Konety BR, Nguyen TS, Dhir R, et al. Detection of bladder cancer using a novel nuclear matrix protein, BLCA-4. Clin Cancer Res 2000;6:2618-2625.

39. Van Le TS, Miller R, Barder T, et al. Highly specific urine-based marker of bladder cancer. Urology 2005;66:125612-125660.

40. Sharp JD, Hausladen DA, Maher MG, et al. Bladder cancer detection with urinary survivin, an inhibitor of apoptosis. Front Biosci 2002; 7:e36-41.

41. Lokeshwar VB, Habuchi T, Grossman, B et al. Bladder tumor markers beyond cytology: International Consensus on bladder tumor markers. Urology 2005;66(Suppl 1):35-63.

42. Lokeshwar VB, Getzenberg RH. Voided urine markers. In: Lerner SP, Schoenberg M, Sternberg $C$, editors. Text book of bladder cancer. London (UK): T\&F-Informa, 2006. p. 65-137

43. Ohsawa I, Nishimura T, Kondo $Y$, et al. Detection of urine survivin in 40 patients with bladder cancer. J Nippon Med Sch 2004;71:379-83

44. Shariat SF, Casella R, Khoddami SM, et al. Urine detection of survivin is a sensitive marker for the noninvasive diagnosis of bladder cancer. J Urol 2004;171:626-630.

45. Hijazi A, Devonec $M$, Bouvier R, et al. Flow cytometry study of cytokeratin 18 expression according to tumor grade and deoxyribonucleic acid content in human bladder tumors. J Urol 1989;141:522-526.

46. Babjuk M, Soukup V, PesI M et al. Urinary cytology and quantitativeBTA and UBC tests in surveillance of patients with pTapT1 bladder urothelial carcinoma. Urology 2008;71:718-722.

47. Mungan NA, Vriesema JLJ, Thomas CMG, et al. Urinary bladder cancer test: A new urinary tumor marker in the follow-up of superficial bledder cancer. Urology 2000;56:787-792.
48. Fernandez-Gomez J, Rodriguez-Martinez JJ, Barmadah SE, et al. Urinary CYFRA 21.1 is not a useful marker for the detection of recurrences in the follow-up of superficial bladder cancer. Eur Urol 2007; 51:1267-1274.

49. Ewing R, Tate GM, Hetherington JW. Urinary fibrin/ fibrinogen degradation products in transitional cell carcinoma of the bladder. $\mathrm{Br}$ J Urol 1987;59:53-58.

50. Jayachandran S, Unni Mooppan MM, Wax SH, et al. The value of urinary fibrin/ fibrinogen degradation products as tumor markers in urothelial carcinoma. J Urol 1984;132:21-23.

51. Wajsman Z, Williams PD, Greco J, et al. Further study of fibrinogen degradation products in bladder cancer detection. Urology 1978;12:659-661.

52. Pirtskkalaishvilli G, Getzenberg RH, Konety BR. Use of urine-based markers for detection and monitoring of bladder cancer. Tech Urol 1999;5:179-184.

53. Johnston B, Morales A, Emerson L. Rapid detection of bladder cancer: A Comparative study of point of care tests. J Urol 1997; 158:2098-2101.

54. Lokeshwar, VB. and Soloway, MS. Current bladder tumor tests: does their projected utility fulfill clinical necessity? J Urol 2001; 165:1067-1077.

55. Schroeder GL, Lorenzo-Gomez MF, Hautmann SH, et al. A side-byside comparison of cytology and biomarkers, HA-HAase, hematuria detection, BTAStat, UBC-Rapid for bladder cancer detection. J Urol 2004; 172:1123-1126.

56. Lokeshwar VB, Obek C, Pham HT, et al. Urinary hyaluronic acid and hyaluronidase: Markers for bladder cancer detection and evaluation of grade. J Urol 2000;163:348-356.

57. Lokeshwar VB, Schroeder GL, Selzer MG, et al. Bladder tumor markers for monitoring recurrence and screening comparison of hyaluronic acid hyaluronidase and BTA-Stat tests. Cancer 2002;95:61-72.

58. Lodde M, Mian C, Comploj E et al. uCyt+ test: alternative to cystoscopy for less-invasive follow-up of patients with low risk of urothelial carcinoma. Urology 2006;67:950-954.

59. Pode, D., Golijanin, D., Sherman, et al. Immunostaining of Lewis $X$ in cells from voided urine, cytopathology, and ultrasound for noninvasive detection of bladder tumors. J Urol 1998;159:389-393.

60. Golijanin D, Sherman, Y, Shapiro A, et al. Detection of bladder tumors by immunostaining of the Lewis $X$ antigen in cells from voided urine. Urology 1995;46:179-177.

61. Sawczuk IS, Pickens CL, Vasa UR, et al. DD23 Biomarker. A prospective clinical assessment in routine urinary cytology specimens from patients being monitored for TCC. Urol Oncol 2002;7:185-190.

62. Gilbert SM, Veltri RW, Sawczuk A, et al. Evaluation of DD23 as a marker for detection of recurrent transitional cell carcinoma of the bladder in patients with a history of bladder cancer. Urology 2003;61:539-543.

63. Golijanin D, Shapiro A, Pode D. Immunostaining of cytokeratin 20 in cells from voided urine for detection of bladder cancer. J Urol 2000;164:1922-1925.

64. Rotem D, Cassel A, Lindenfeld N. et al. Urinary cytokeratin 20 as a marker for transitional cell carcinoma. Eur Urol 2000;37:601-604.

65. Bavaccini S, Casadio V, Amadori A, et al. The current role of telomerase in the diagnosis of bladder cancer. Indian J Urol 2005;25:40-46.

66. Ito $H$, Kyo S, Kanaya $T$, et al. Expression of human telomerase subunits and correlation with telomerase activity in urothelial cancer. Clin Cancer Res 1998;4:1603-1608.

67. Kim NW, Piatyszek MA, Prowse KR, et al. Specific association of human telomerase activity with immortal cells and cancer. Science 1994;266:2011-2015.

68. Chen $\mathrm{CH}$, Chen RJ. Prevalence of telomerase activity in human cancer. J Formos Med Assoc 2011;110:275-289.

69. Eissa S, Swellam M, Ali-Labib R, et al. Detection of telomerase in urine by 3 methods: evaluation of diagnostic accuracy for bladder cancer. J Urol 2007;178:1068-1072. 
70. Wu XX, Kakehi Y, Takahashi T, et al. Telomerase activity in urine after transurethral resection of superficial bladder cancer and early recurrence. Int J Urol 2000;7:210-217.

71. Yokota K, Kanda K, Inoue $Y$, et al. Semi-quantitative analysis of telomerase activity in exfoliatedhuman urothelial cells and bladder transitional cell carcinoma. Br J Urol 1998;82:727-732.

72. Lee MY, Tsou MH, Cheng MH, et al. Clinical application of NMP22 and urinary cytology in patients with hematuria or a history of urothelial carcinoma. World J Urol 2000;18:401-405.

73. Weikert S, Krause $\mathrm{H}$, Wolff I, et al. Quantitative evaluation of telomerase subunits in urine as biomarkers for noninvasive detection of bladder cancer. Int J Cancer 2005; 117:274-280.

74. Sanchini MA, Gunelli R, Nanni O, et al. Relevance of urine telomerase in the diagnosis of bladder cancer. JAMA 2005;294:2052-2056

75. Hijazi A, Devonec M, Bouvier R, et al. Flow cytometry study of cytokeratin 18 expression according to tumor grade and deoxyribonucleic acid content in human bladder tumors. J Urol 1989;141:522-526.

76. Babjuk M, Soukup V, Pesl $M$, et al. Urinary cytology and quantitativeBTA and UBC tests in surveillance of patients with pTapT1 bladder urothelial carcinoma. Urology 2008;71:718-722.

77. Skacel M, Fahmy M, Brainard JA, et al. Multitarget fluorescence in situ hybridization assay detects transitional cell carcinoma in the majority of patients with bladder cancer and atypical or negativ e urine cytology. J Urol 2003;169:2101-105.

78. Gofrit ON, Zorn KC, Silvestre J, et al. The predictive value of multitargeted fluorescent in-situ hybridization in patients with history of bladder cancer. Urol Oncol 2008;26:246-249.

79. Sarosdy MF, Schellhammer P, Bokinsky G, et al. Clinical evaluation of a multi-target fluorescent in situ hybridization assay for detection of bladder cancer. J Urol 2002;168:1950-1954.

80. Catto JW, Alcaraz A, Bjartell AS, et al. MicroRNA in prostate, bladder, and kidney cancer: a systematic review. Eur Urol 2011;59:671-681.
81. Valadi H, Ekstrom K, Bossios A, et al. Exosome-mediated transfer of mRNAs and microRNAs is a novel mechanism of genetic exchange between cells. Nat Cell Biol 2007;9:654-659.

82. Hanke M, Hoefig K, Merz $\mathrm{H}$, et al. A robust methodology to study urine microRNA as tumor marker: microRNA-126 and microRNA-182 are related to urinary bladder cancer. Urol Oncol 2010;28:655-661.

83. Catto JW, Miah S, Owen HC, et al. Distinct microRNA alterations characterize high- and low-derece bladder cancer. Cancer Res 2009;69:8472-8481.

84. O'Sullivan P, Sharples K, Dalphin M, et al. A multigene urine test for the detection and stratification of bladder cancer in patients presenting with haema $\neg$ turia. J Urol 2012;188:741-747.

85. Miah S, Dudziec E, Drayton RM, et al. An evaluation of urinary microRNA reveals a high sen $\neg$ sitivity for bladder cancer. $\mathrm{Br}$ J Cancer 2012;107:123-128.

86. Steiner G, Schoenberg MP, Linn JF, et al. Detection of bladder cancer recur-rence by microsatellite analysis of urine. Nat Med 1997;3:621-624.

87. Van der Aa MN, Zwarthoff EC, Steyerberg EW, et al. Microsatellite analysis of voided-urine samples for surveillance of low-grade nonmuscle-invasive urothe $\neg$ lial carcinoma: feasibility and clinical utility in a prospective mul-ticenter study (Cost-Effectiveness of Follow-up of Urinary Bladder Cancer trial [CEFUB]). Eur Urol 2009;55:659-667.

88. Wosnitzer MS, Domingo-Domenech J, Castillo-Martin M, et al. Predictive value of microtubule associated proteins tau and stathmin in patients with nonmuscle invasive bladder cancer receiving adjuvant intravesical taxane therapy. J Urol 2012;186:2094-2100.

89. Acikalin D, Oner U, Can C, et al. Predictive value of maspin and Ki-67 expression in transurethral resection specimens in patients with T1 bladder cancer. Tumori 2012;98:344-350.

90. Gkialas I, Papadopoulos G, lordanidou L, et al. Evaluation of urine tumor-associated trypsin inhibitor, CYFRA 21-1, and urinary bladder cancer antigen for detection of high-grade bladder carcinoma. Urology 2008;72:1159-1163. 